Max-Planck-Institut für demografische Forschung

Max Planck Institute for Demographic Research

Konrad-Zuse-Strasse 1 - D-18057 Rostock · GERMANY

Tel +49 (0) 3812081 - 0; Fax +49 (0) 3812081 - 202;

http://www.demogr.mpg.de

MPIDR WORKING PAPER WP 2003-026

JULY 2003

\title{
Education and union formation as simultaneous processes in Italy and Spain
}

Lucia Coppola (lcoppola@istat.it)

This working paper has been approved for release by: Jan M. Hoem (hoem@demogr.mpg.de)

Head of the Laboratory of Contemporary European Fertility and Family Dynamics.

(c) Copyright is held by the authors.

Working papers of the Max Planck Institute for Demographic Research receive only limited review. Views or opinions expressed in working papers are attributable to the authors and do not necessarily reflect those of the Institute. 


\title{
Education and union formation as simultaneous processes in Italy and Spain
}

\author{
Lucia Coppola \\ ISTAT - Italian National Statistical Institute \\ Via Cesare Balbo 16, 00184 Roma, Italy \\ lcoppola@istat.it
}

\begin{abstract}
In recent times, both the time spent on education and the age at first union formation have significantly increased in Italy and Spain. In this paper, we provide empirical evidence of the endogeneity of the two processes. We use Panel data (European Community Household Panel), which provide detailed standardised information for both countries about education and training processes as a well as household formation. The effect of unobservable characteristics affecting the two processes at the same time has been controlled for, using simultaneous hazard modelling. On the one hand, the exit from the educational system increases the risk of entering the first union. On the other hand, there exist individual unobserved characteristics that influence the occurrence of the two processes simultaneously. If these characteristics are not controlled for, the effect of a completed education on union formation becomes biased upward.
\end{abstract}

\section{Introduction}

Educational career and union formation represent two important processes shaping the transition from childhood to adulthood. The study of such processes is particularly interesting in Italy and Spain, where marriages have increasingly been postponed, the emergence of cohabiting unions is still limited, fertility is at "lowest-low" levels, and the duration of an individual's education is increasingly prolonged (De Sandre et al., 2000; Ongaro, 2001; Sabbadini, 1997; Kohler et al., 2001; Delgado and Castro Martin, 1999; Baizan, 2001; Tobio, 2001). These two trajectories are part of the individual's life course strategy: decisions affecting one process are potentially also affecting the other. Thus, in order to understand each process, it is important to take into account the causal reciprocal relationship, and at the same time to control for the possible existence of factors that determine both processes simultaneously.

The literature is rich in theoretical and empirical studies that show how enrolment in school and the educational level affect the timing and occurrence of union formation. For instance, prolonged investments in human capital decreases women's gain from marriage (Becker, 1991) and delays the transition to economic stability that is needed before forming a union (Oppenheimer, 1988). Enrolment in education delays the entry into first union (Liefbroer and Corijn, 1999; Hoem, 1986) not only due to economic reasons, but also because of the effect of social norms which generate the incompatibility between the youth role of being a student, and the adult role implied by marital status (Blossfeld and Huinink, 1991).

In the literature, we also find evidence for the reverse effect of union formation on school progression. Indeed, it has been shown that once an individual enters a union, he or she is 
exposed to a higher risk of ending school (Davis and Bumpass, 1976; McLaughlin et al., 1986), and that such effects are stronger for women than for men (Marini, 1978; Alexander and Reilly, 1981; Teachman and Polonko, 1988).

Once the mutual relations between the two processes are taken into account, the existence of common factors which influence the processes simultaneously must be tested. Indeed, the processes have been shown to be endogenous in the sense that there exist unobservable characteristics which simultaneously determine individual choice about both union formation and educational attainment (Boulier and Rosenzweig, 1984; Sander, 1992; Lillard et al., 1994).

In this paper, the processes of first union formation (without distinguishing between marriage and consensual unions) and final exit from education are modelled, using transition rate models (Blossfeld and Rower, 1995), employing both individual and household characteristics as explanatory variables. Moreover, simultaneous hazard modelling (Lillard, 1993) is used in order to control for the existence of unobservable factors affecting both processes.

We use data from the European Community Household Panel (ECHP). Such data provides for both countries standardised information about characteristics of the household and of the individual which can affect the processes under study.

The paper is structured as follows: In section 2, the theoretical background that supports the hypothesis of interrelation between the processes and their common determinants is outlined. In section 3 the existing literature about household formation and educational career in Italy and Spain is reviewed. Section 4 discusses the data and the methods implemented. In section 5 the results are reported, focusing on the interrelation between the processes, and on their endogeneity. Finally, in section 6, the main findings are summarised.

\section{Theoretical framework}

In the literature, the effect of individual and household characteristics on union formation and educational progression processes has been widely explored. But, since we mainly want to focus on the causal effect of each process on the other, we will discuss in this section only the theoretical background that supports our hypothesis: the existence of a strong interrelation between the two life trajectories that lead to first union and exit from education.

In particular, we assume that entry into first union triggers an early end of education (section 2.1), and conversely, that educational enrolment delays the transition to first union (section 2.2). Moreover, we assume that there might exist unobservable characteristics that simultaneously affect both processes, and that it is necessary to control for them in order to get an unbiased picture on the mutual relationship (section 2.3). 


\subsection{The effect of education on union formation}

An important issue, in terms of the interpretation of the effects of education on union formation, is the different impact of enrolment and actual attained level. The literature has indeed shown that differentiated treatment of these effects is crucial, both in terms of occurrence, as well as the timing of a union.

The empirical evidence showing that educational enrolment tends to delay the formation of the first union is substantial (Liefbroer and Corijn, 1999; Hoem, 1986; Blossfeld and Huinink, 1991; Goldscheider and Waite, 1986). Education influences an individual's ability to enter a stable union in different ways. First, when attending school or university, individuals are normally not financially independent, and to a large extent they have to rely on their family's financial support. Consequently, they do not have the resources to cover the costs incurred by the formation of a household.

On the other hand, Blossfeld and Huinink state that "there exist normative expectations in society that young people who attend school are 'not at risk' of entering marriage or parenthood' (1991). As they argue, the postponement of unions is related to school enrolment, which in turn is driven by the existence of social norms. Such "sequencing" norms concern the incompatibility of educational and marital or cohabitation roles. Indeed, education is considered a youth role, while marriage is associated with an adult role. Marini (1984) argues for instance, that the presence of sequencing norms generates a preference for union formation taking place after the educational process is finished. Furthermore, unions should take place after the young individual has ensured a secure position in the labour market, and has achieved a stable economic position (Oppenheimer, 1988).

While the individual is enrolled in the educational system, it is not clear to what extent he or she is able to enter adult roles. This kind of uncertainty affects the mating process. For instance, it is difficult to predict the expected quality of a match that is formed at this life stage. Many of the "adult" characteristics are still not observable and not easily predictable. A confirmation of this comes from the evidence that school enrolment affects the timing of marriage in a much stronger way than with respect to the formation of consensual unions (Thornton et al., 1995; Clarkberg, 1999). This is related to the fact that cohabitation generally involves a lower commitment than marriage, and that the opportunity costs of cohabitation may be lower than those of marriage (Oppenheimer, 1994).

It is reasonable to assume that education impacts men's and women's union formation processes in the same way, because it represents a barrier to the psychological, social and economical transition to adulthood for both genders. The effect of the educational level however can be subject to gender differences. In reality, prolonged school enrolment is associated with high levels of education, which in turn provide the means to get a stable occupational position 
quickly, once the individual has entered the labour market (Oppenheimer, 1988). The improved opportunities for economic success and self-realisation can affect women's and men's interest for union formation in different ways.

For instance, men with a higher educational level and better socio-economic position are more attractive in the marriage market. Consequently they will receive a higher rate of marriage offers, which makes it easier for them to find a high quality partner. Furthermore, a consequence of their strong economic position is that they are in a better position to afford the costly venture of setting up their own family. Women with high educational levels may also be considered as more attractive in the marriage market. But it is clear that their strong economic position makes them value the potential benefit of marriage as lower, compared to women with lower levels of education. Although the increased investments in human capital represent a means of establishing their economic position, it also means that women perceive a high cost in the form of having to spend their time on household intensive activities such as child rearing (Becker, 1973; Becker, 1991, ch.II; Oppenheimer, 1988). Therefore, in a social context where women show increasing interest in human capital accumulation and attachments to the labour market, one is likely to expect a postponement of marriages or consensual unions or even a reduction in their frequencies.

Naturally, the educational level will also represent an individual's characteristic, affecting the mating process itself. Indeed, a partner's educational level is considered a complementary trait that will reinforce the quality of the union. The more similar educational levels are, the better the quality of the union (Becker, 1973). Empirical evidence suggests that highly educated women tend to marry men with the same or higher levels of education, while men tend to marry women with the same or lower levels (Gonzalez, 2000). As women increase their educational level, this mating pattern will be more difficult, possibly lowering their marriage rates.

\subsection{The effect of first union formation on the termination of education}

Many studies have shown that the adoption of family behaviours typical of adult ages leads to a higher risk of leaving the educational system. For example it has been found that forming a union (Davis and Bumpass; 1976; McLaughlin et al., 1986) or having a child (Waite and Moore, 1978; Marini, 1984b; Upchurch and McCarthy, 1990) induce early drop out from school. Some studies show that there are differences among genders as to how union formation affects educational advancement. In this regard, the evidence suggests that union formation has a higher impact on women than on men (Marini, 1978; Alexander and Reilly, 1981; Teachman and Polonko, 1988). 
We have argued that the presence of sequencing norms, economic uncertainty among young adults, as well as women's opportunity costs are important in explaining the reduced probability of union formation while being enrolled in the educational system. The same arguments can be used in order to understand the effect of first union formation on educational enrolment.

For instance, marriage prior to the completion of formal education generally violates the common sequencing norms (Marini, 1984). If a union is formed before marriage, partners will feel, in particular, the pressure of social norms reflecting the incompatibility between full time educational enrolment and union formation (Blossfeld and Huinink, 1991; Thornton et al., 1995). Consequently, once in a union, they can decide to accelerate their transition from the educational system to the labour market. Therefore, they are likely to end education quicker than if they were not in a union.

On the other hand, people who start a union while studying may possibly be highly familyoriented. We can assume that family values are likely to cause an individual to break the social norms characterising the relationship between union formation and schooling. Therefore, once they have started forming a household, they will probably desire to quickly experience other transitions to adult roles by leaving the education system and entering the labour market.

The entry into the labour market represents an important step in the union formation process. In fact, union formation is a costly process. Therefore, economic needs, as well as the desire to reach a certain quality of life, could induce people to leave the education system in order to acquire a stable economic position. Such a need can be stronger for men than for women given that men's economic positions have a stronger effect on union formation and its timing (Oppenheimer, 1988).

Finally, if it is true that gender specialisation in family activities maximises the gain from marriage (Becker, 1973; Becker, 1991, ch.II), then both men and women benefit from dropping out of school after having entered a union, but for different reasons. Men would be better off specialising in market activities, while women would be better off specialising in household work. In both cases, after having established their own family, both men and women benefit from leaving the education system and from specialising in other activities.

\subsection{Common factors affecting the timing of union formation and the length of education}

We have argued that union formation and education are processes that influence each other. The roles of 'partner' (especially husband or wife) and of 'student', being hardly compatible, usually imply that transitions in one trajectory trigger transitions in another trajectory. Indeed, the enrolment in education has been shown to reduce rates of entry into union, while entry into union 
triggers an end of education. This means that individual choices about one process also influence his or her choices about the other.

We have already underlined the importance of social norms in determining individual behaviour. But even if every social environment has its set of norms that are supposed to be the same for everybody, each individual still develops his or her own value orientation, tastes and his or her own goals, through which he or she realises his or her own well-being. Empirical studies have shown the existence of selection effects: Individual value orientations are predictors of the occurrence of events (Lesthaeghe and Surkyn, 1988; Lesthaeghe and Moors, 1995; Lesthaeghe and Vanderhoeft, 1997).

Concerning family formation and investment in family life, value orientations will affect behaviour in a predictable way. Highly family-oriented individuals tend to opt for educational and job careers that allow them to form a family quickly (including a union). In contrast, people who are highly career-oriented tend to place emphasis on educational and job careers that are less likely to leave room for early family formation. Thus, they are less likely to enter a union compared to more traditionally oriented people, and they also behave in a more individualistic way once in a union (Jansen and Kalmijn, 2002).

Therefore, value orientation (usually unobserved in the type of surveys now available) influences the decision making processes of individuals and this should be taken into account in order to achieve unbiased results when analysing the reciprocal impact of individual processes. Thus controlling for unobservable characteristics is necessary when direct measures of individual characteristics such as value orientations are not available.

Using an instrumental variable approach, Sander showed in 1992 that education is endogenous to family decisions such as marriage and divorce, and that educational enrolment must therefore be modelled as an endogenous variable when estimating the risk of getting married. If this endogeneity is ignored, the negative effect of education upon marriage is underestimated.

Other studies using simultaneous modelling strategies also demonstrate the endogeneity issue. Boulier and Rosenzweig (1984) present a model in which education and age at marriage are two processes dependent on the labour and marriage market as well as on unobservable individual characteristics that are consequently represented through a random heterogeneity term. Finally, a mating function is estimated as being dependent on the other two processes and on individual unobserved characteristics. The empirical application of this model to Philippine data shows that "schooling, marital search and spouse selection are endogenous variables influenced directly or indirectly by the total resources of parents, endowed traits of offspring, the cost of schooling, and marriage market conditions".

Lillard and colleagues (Lillard et al., 1994; Upchurch et al., 2001) assume that education and family formation behaviours are related in two main ways. Firstly there are direct cross effects. 
For instance, school enrolment reduces economic independence and consequently the capacity of getting married, while being married could increase the cost of continuing one's education (as argued in the previous two sections). Secondly, the allocation of time between schooling and family formation is driven by individual preferences for both kinds of activities, and for their future consequences. The authors find a negative (significant) correlation between marriage formation and educational enrolment. Therefore the same unobservable influence both marriage and education processes but in opposite directions. On the one hand, getting married reduces the likelihood of advancing one's education at all levels, apart from marriage during high school. On the other hand, the probability of getting married increases when leaving school. Conditioning on age, the increase of the risk does not vary much with completed educational level. This shows that a higher propensity toward family formation results in lower investments in human capital, and vice versa.

\section{Schooling and union formation in Italy and Spain}

This paper aims not only at studying the mutual relationship between first union formation and the exit from education processes, but also aims at re-interpreting this relationship once endogeneity is taken into account. Conversely, we are not particularly interested in the potential country specific impact of socio-cultural and institutional characteristics on the processes under study, and on their relations. Therefore, we develop the analysis for two "similar" countries, and we use not a comparative but a "confirmative" approach. In this way, results obtained in the two countries reinforce each other. Italy and Spain represent two countries particularly well adapted for this purpose.

Italy and Spain represent the prototypes of the so called "Mediterranean" or "southern European" societies. On the one hand, Italy and Spain are characterised by strong similarities in welfare systems and institutional settings, which rely mostly on the family (Esping-Andersen, 1999). Reher (1998) stresses the strength of family ties in such countries, in contrast with much weaker ties in other northern European countries. On the other hand, they are characterised by similar socio-demographic patterns that involve all the family formation processes such as the so called "latest-late" transition to adulthood (Billari et al., forthcoming), as well as similar participation in labour force and education systems (De Sandre et al., 2000; Delgado and Castro Martin, 1999; Eurostat, 1997; Eurostat, 2000).

Regarding the processes we are interested in, Italy and Spain constitute a particularly interesting context for studying the relationship between union formation and education. In both countries, a massive expansion of women participating in education has been observed, as we 
will discuss in the following sections. At the same time, unions have been significantly postponed, and not compensated for the increased popularity of cohabitation.

Here we discuss the results in the literature for Italy and Spain in turn.

\subsection{Italy}

Italy has been characterised by an increase in the general level of education in the population over the past decades. In 1951 only 5 per cent of men, and 3 per cent of women, in the total population had a secondary or post secondary level of education. In 1991 this had increased to 24 and 22 per cent respectively (De Sandre et al., 2000). On the one hand, this trend can be seen as the consequence of the increased age for compulsory education, fixed by law at 14 years in 1968. On the other hand, criteria for university entrance were eased in 1969, and in the following years the number of regional universities was expanded, making it easier to attend higher education (Ongaro, 2001). Especially women increased their participation in the educational system. In fact, by 1988 more women than men participated in higher education. In 1995, 52 per cent of students in higher education were women (Eurostat, 2000).

In this context of educational and social transformation, which sees women increasingly active and emancipated and assuming roles and lifestyles more similar to those of men, nuptiality trends have also changed. First marriages in Italy have been characterised by a decline of the first marriage rate from 78 per cent in 1990 to 60 per cent in 1997. At the same time, the mean age at first marriage increased for both genders from 27.1 in 1980 to 30.0 in 1998 for men and from 23.9 in 1980 to 27.1 in 1998 for women (Eurostat, 1997). Such trends are even more significant when taking into account that the decrease and postponement of marriages are not compensated by the diffusion of alternative forms of unions, such as cohabitation, that have been spreading substantially in other countries (Sabbadini, 1997).

Some empirical analyses examined the determinants of the Italian marriage model. Having a job, and consequently being economically independent, speeds up union formation for men. For women, however, having a job seems to have the opposite effect (Ongaro, 2001). Individuals with a high level of education marry less and later, and this is the case for both women and men (Castiglioni, 1999). In particular for women, it has been shown that both schooling enrolment and the level of education are associated with the postponement of marriage. Therefore the increase of the female educational level would be one of the causes of the postponement of marriage in Italy. This seems to be mainly associated with delays in the transition to adulthood but only as a consequence of the postponement of marriage (Blossfeld and De Rose, 1992). Indeed, Italy is one of the countries where young people stay longer in their family of origin and 
when they leave home, it is usually simultaneous to the entry into a marriage or consensual union (De Sandre, 1997; Billari and Ongaro, 1999).

Value orientations have been indicated as determinants of the postponement of first unions, although existing surveys do not allow for the identification of the issue responsible. Indeed, women who have a less traditional value orientation, who believe that marriage is an old fashioned institution and that out-of-wedlock births are acceptable, marry late or less frequently. For men however the level of traditionalism seems not to have any effect. Moreover, individual preference for high levels of consumption is associated with lower risk of entry into marriage, and this is true for both men and women (Castiglioni, 1999). It is worth noting that these results on the effects of individual value orientation and attitudes can be biased. Indeed, individual value orientation is defined according to information collected after the events took place. Therefore it is not possible to establish the causal relationship between current value orientations and previous life experiences. In other words, individuals who have experienced unsatisfying unions are less likely to be family oriented at the moment of the interview. In this case the actual value orientation would be based on previous life experiences, and it would be incorrect to use actual value orientations to explain previous behaviours. Consequently there is a need for an alternative mechanism to control for the effects of these unobserved characteristics. The approach we propose in this paper is to model these characteristics as random unobserved heterogeneity terms.

Finally, marriage timing in Italy is also influenced by social norms. Indeed, it has been shown that there is a high level of perception and of internalisation of the "proper age" to marry. Also norms on age limits are widely spread in the population, particularly for what concerns a lower limit for marriage (that is also imposed by law) (Billari and Micheli, 2001).

\subsection{Spain}

During the lasts decades, Spain has experienced many constitutional, social and economic transformations. The reform of the Civil Code in 1981 is particularly relevant, and was introduced in order to adapt the Civil Code to the Constitution of 1978. Before the reforms took place, the concept of family was based, by definition, on masculine authority and women's dependence. "Marriage was conceived as a sacrament with civil and administrative effects, which justified differences between children born in and out of marriage" (Tobio, 2001). Divorce was only legalised in 1981. According to the new constitution, women and men have the same rights in marriage and all children are legally equal, independently of the marital status of their parents. Therefore married and unmarried parents have the same obligations towards their children. This reform has been the basis for the adoption of a more European trend in Spain, narrowing gender roles, increasing the emancipation of women and their participation in the 
labour market, and for allowing new forms of union such as cohabitation and out of wedlock childbirth.

During the second half of the 1900's, the Spanish educational system was transformed, providing a higher level of education for both women and men, resulting in a sharp reduction of illiteracy. "The steady improvement in the access to longer and better schooling has brought about a sizeable durational gap among adjacent generations. Furthermore, not only have women in recent years matched men in higher education enrolments, they have even slightly surpassed them" (Delgado and Castro Martin, 1999). Indeed, the percentage of women in higher education is as high as 53 in 1996.

In the new socio-economic context, marriage patterns have changed as well. The last decades have been characterised by a postponement of first union (Castro Martin, 1993; Baizan, 2001; Tobio, 2001). The age at first marriage increased during the last years from 23.5 in 1980 to 27.4 in 1998 for women, and from 25.9 in 1980 to 29.4 in 1998 for men (Eurostat, 1997). The decline of marriage rates and the postponement of first marriage, as observed in other European countries, does not correspond to an equivalent increase in cohabitation. Indeed, if in other countries cohabitations compensate for the lack of marriages, this has not taken place in Spain nor Italy, where consensual unions are still relatively rare.

Spain, as Italy, is a country characterised by very late transition to adulthood: late age at leaving school, late age at first job and late age at leaving home (Baizan, 2001). Late age at leaving school is attributable to prolonged education, and an increase in educational facilities at different levels (Tobio, 2001). Empirical analyses demonstrate the importance of education in determining the late age at first marriage. This is true especially for women, where "college education leads to marriage postponement, but it does not reduce the likelihood of eventual marriage after school completion" (Castro Martin, 1993). As for men, individuals in secondary education have a lower risk of entering marriage than those with primary or university education. High levels of individual income are associated with earlier age at marriage (Baizan, 2001).

The traditional and conservative behaviour of young people in Spain seems to be in contrast to the high level of tolerance they have for non-traditional behaviours. Indeed, the majority of young Spaniards favours different kinds of unions, like cohabitation, or homosexual partnerships, as well as non-marital childbirth (Tobio, 2001). 


\section{Data and methods}

\subsection{The European Community Household Panel (ECHP)}

Our analyses will be developed using data from the "European Community Household Panel" (ECHP). This is a multi-dimensional and multi-purpose survey centrally designed and coordinated by the Statistical Office of the European Community (EUROSTAT). It is carried out by National Data Collection Units (NDU), that is the national institutes of statistics or other public bodies or private organisation. In Italy and Spain the national institutes, ISTAT and INE respectively, are responsible for the survey. The ECHP has been carried out from 1994 to 2002. For the present analyses, data from 1994 to 1998 are used (Eurostat, 2001).

The survey is representative of the population of the EU countries, at the household and at the individual level, both cross-sectionally and longitudinally. The target population is that of private households, defined as "sharing the same dwelling" and having "common living arrangements". Some information is collected about the household, such as the composition of the household, the financial situation and certain characteristics of the accommodation. Moreover, all members of each household, if older than 16 years, are personally interviewed every year. They are followed up when they leave their original household and form a new one (Istat, 2001). Individuals entering a sample household after the first wave are interviewed as well. Information at the individual level concerns general demographic characteristics, employment, unemployment, education and training careers, income and health status, migration trajectory and certain levels of satisfaction.

The survey provides standardised information for both Italy and Spain (and obviously the other countries that participate in the project), about the different demographic and socioeconomic trajectories of the individuals interviewed. Therefore the ECHP represents a valid instrument with which to analyse the educational career and union formation processes, allowing for conditioning on individual and household characteristics in a comparative framework.

Selected for the analysis are those who, at the first interview, have never been married, are not in a consensual union, are studying and living in the household of origin. In this way the analyses are developed on individuals who, during the period of observation, are concurrently exposed to the risks of entering a union and of ending education. This preliminary condition allows for a simultaneous modelling of the two processes; controlling for the unobservable characteristics that may concurrently influence the exit from education and the entry into union. Finally, the choice to select only individuals who at the time of the first interview were living with their parents is based on the evidence that very few individuals were not in this situation. Hence, except in a few cases, it was possible to introduce characteristics of the family of origin 
into the models. It will be shown later (section 5.2) that household characteristics are useful for the interpretation of the processes, and therefore such assumption finds empirical justification.

For the individuals we selected we reconstructed educational careers according to the monthly calendar of activities available in the ECHP. The definitive exit from education has been defined as being out of the educational system for at least 5 months. For men, military service has been controlled for: individuals who were in education before and after military service were considered continuously enrolled in education. This choice is based on the fact that military service was compulsory in Italy and Spain during the years of the survey, and therefore the exit from education for this reason is not determined as a voluntary decision to stop studying.

We also reconstructed the date of the entry into first union. We do not distinguish between first marriage and consensual union because the entries into cohabitation were too few to allow for modelling the two kinds of union separately. Furthermore, when the individual enters a consensual union, it is not possible to know if it is the first one or not. Nevertheless, all consensual unions observed are assumed to be first unions. It is not too unlikely that individuals still in education are experiencing the first union and not the second or the third one. Thus the results reported in this paper are estimated on a sub-sample of 1347 Italians and 1136 Spaniards who, in the period of observation, experienced 85 and 62 events of "first union" respectively (Tab. 1).

\subsection{Hazard model and simultaneous modelling}

We have argued that union formation and exit from the education system are processes that influence each other. Therefore, when modelling union formation, it is important to take into account the educational career, and vice versa. Also, the eventual existence of unobservable factors that could influence both processes simultaneously has been underlined, and therefore must be taken into account.

The literature that deals with modelling different interrelated trajectories, like union formation and educational careers, constitutes a vivid debate about the appropriate way of modelling these processes. The "causal" approach suggests that it is sufficient to model each process separately, conditioning on past trajectories of each process (Blossfeld and Rohwer, 1995). A contrasting approach stresses the importance of modelling the processes simultaneously as in a system, allowing for the correlation among the heterogeneity terms of each process (Lillard, 1993). Such heterogeneity, it is claimed, represents the set of unobservable individual characteristics that affects individual choices, and this can be interpreted in terms of attitudes and

value orientations. In this paper both approaches will be used in order to find the best descriptions of both processes and their interrelationship. 
Thus in the first step each process is modelled through a hazard equation, conditioning on household and individual covariates as well as on the other process.

In particular, first union formation is modelled as follows.

$$
\ln h^{u}(t)=\alpha_{0}+A_{u}(t)+\alpha_{1}^{\prime} X\left(t_{1}\right)+I\left(t_{1}\right)+\alpha_{3} E(t)
$$

where:

- $t$ stands for the age of the individual minus 16 which is the minimum age at interview in the ECHP, and it represents the minimum age at the exposure to experience the event of interest

- $\quad h^{u}(t)$ denotes the hazard of entry into first union (starting at age 16)

- $\quad A_{u}(t)$ denotes the effect of age. It is represented by a linear spline with a knot at 24 years

- $\quad X\left(t_{1}\right)$ is a vector of household and individual covariates measured at the first wave, at which time the respondent has age $t_{1}$. They include sex, educational level, being a member of a club such as a sport or entertainment club, a local or neighbourhood group, a party etc., and level of satisfaction with the amount of leisure time.

- $I\left(t_{1}\right)$ denotes household income at age $t_{1}$. It is represented by a linear spline with a knot at the mean per capita income in the sample. It is computed as the household income divided by the equivalised size of the household (OECD scale). It is thus expressed in purchasing power parities.

- $E(t)$ is the time dependent covariate that expresses whether the individual has left the educational system at time $t$

Exit form the educational system is modelled as follows.

$$
\ln h^{e}(t)=\beta_{0}+A_{e}(t)+\beta_{2}^{\prime} Z\left(t_{1}\right)
$$

where:

- $\quad t$ stands for the age of the individual (minus 16).

- $\quad h^{e}(t)$ denotes the hazard of the exit from the educational system (starting at age 16)

- $\quad A_{e}(t)$ denotes the effect of age. It is represented by a linear spline with knots at 19 and 25 years (about when individuals are supposed to leave high school and university, respectively).

- $Z\left(t_{1}\right)$ is a vector of household and individual covariates measured at the first wave, at which time the respondent has age $t_{1}$. They include household income, the father's educational 
level, the level of satisfaction with studying and the number of individuals per room in the home (kitchen excluded).

In a second model, a heterogeneity term is added to each process: $\varepsilon^{u}$ for union formation and $\varepsilon^{e}$ for exit from education. Each term represents unobserved characteristics at the individual level ${ }^{1}$. They are normally distributed with the mean equal to 0 and the variance equal to $\sigma_{u}^{2}$ and $\sigma_{e}^{2}$ respectively.

Since we are interested in the possible correlation between the unobservable characteristics that affect the two processes, we fix the variance ${ }^{2}$ of each process and then estimate the correlation among the heterogeneity terms.

The heterogeneity terms are assumed to be time-constant. Such an assumption is not necessarily restrictive given that the period of observation of the individuals is 4 years. All in all we assume that

$$
\left(\begin{array}{l}
\varepsilon^{u} \\
\varepsilon^{e}
\end{array}\right)=N\left(\left(\begin{array}{l}
0 \\
0
\end{array}\right),\left(\begin{array}{cc}
\sigma_{u}^{2} & \rho \sigma_{u} \sigma_{e} \\
\rho \sigma_{u} \sigma_{e} & \sigma_{e}^{2}
\end{array}\right)\right)
$$

The models are estimated at maximum likelihood, using the aML software package (Lillard and Panis, 2000). In order to evaluate the quality of the models the BIC (Bayesian Information Criterion) will be used (Raftery, 1995), because it allows for comparison among non-nested models. The lower is its value, the better is the model. Moreover, this indicator is more suitable than ln-likelihood when the processes we are modelling are characterised by the occurrence of just few events.

\footnotetext{
${ }^{1}$ Some of our respondents belong to the same household. Therefore, it can be argued that these observations are not independent, but that there should be a possible correlation among those in the same family. In order to check such a hypothesis, a multilevel model that takes into account the hierarchy in the data has been estimated, with the heterogeneity term representing the variability at the household level. These results confirmed that the observations could indeed be considered independent. Therefore, the models presented are estimated at an individual level.

${ }^{2}$ Given that we are modelling single spell processes, and that we do not include any time-varying explanatory variable in the models, we do not have enough information to directly estimate the variance terms. Therefore, we fix the variance terms at different values, and we notice that the estimates of the correlation is stable. Indeed, the estimate of the correlation does not vary depending on the values of the variance terms.
} 


\subsection{Explanatory variables}

In order to explain the processes of first union formation and exit from education, the effect of several explanatory variables is tested. In particular, we will focus on the effect of some individual characteristics and some household characteristics on the risk of experiences the two events under examination. Concerning exit from education, because of lack of information, we are not able to distinguish between the completion of an education period (by attaining a vocational certificate or degree) and drop out of education (by not attaining such a result). Although the difference between these two ways of leaving the educational system is important in shaping the process, we have to disregard this aspect. Thus we discuss the effect of the possible explanatory variables on the duration of school enrolment, not referring to the possible reason of its end.

First, concerning individual characteristics, the effect of age and sex is controlled for. Indeed, both processes are supposed to be highly dependent on age. Trends of marriage by age are well defined both in Italy and Spain, by a non-monotonic pattern: The risk of entering a union rises with age, reaches a peak, and then falls (Castiglioni, 1999; Righi, 1997; MiretGamundi, 1997). Also school enrolment is dependent on age, given that in both countries a minimum age, below which everyone must go to school, is defined by law. Concerning gender differences, we expect that union formation is highly differentiated by sex, with men entering the first union later (Castiglioni, 1999; Righi, 1997; Miret-Gamundi, 1997). The literature has shown that, through and increasing participation of women in the educational system, nowadays the process of exiting from education occurs in a similar shape for both genders (Ongaro, 2001; Delgado and Castro Martin, 1999; Eurostat, 1997).

The other individual characteristics taken into account are levels of satisfaction, in particular the level of satisfaction with studying, with the financial situation, with the housing situation and with the amount of leisure time. The literature recognises an important role of satisfaction levels with several aspects of life. Such variables have been investigated both in terms of dependent variables and of independent variables. Concerning the relationship between marital status and satisfaction, the former is usually considered as a cause of the latter, married individuals being more satisfied than those in the other civil status (Stack and Eshleman, 1998 Ryan, 1981; Broman; 1988).

As an independent variable, satisfaction is important in determining decision making processes about migration (Speare, 1974; Morris et al., 1976), job change (Akerlof et al., 1988; Freeman, 1978), education drop-out (Bean, 1980; Spady, 1970; Tinto, 1975) and so on. In particular, when the theory was applied to residential mobility it was discovered that highly satisfied individuals are not likely to move, while beyond a certain threshold of dissatisfaction individuals desire to change their residential situation, and only at a very high level of 
dissatisfaction would they actually move (Speare, 1974; Morris et al., 1976; Landale and Guest, 1985). Similarly, we assume that those individuals who are highly satisfied with the different aspects of their current situation are less likely to experience a desire to change their current situation, as is the case at the establishment of the first union. In particular, those who are satisfied with studying might be motivated to invest more in the educational career, and postpone the first union. Those who are satisfied with their financial and housing situation (which concerns the family of origin) might postpone leaving home until they are able to acquire their own housing and financial situation at the same level of satisfaction as the original one. Those who are satisfied with the amount of leisure time in their lives might be less motivated to start assuming the responsibilities implied by household formation. The effect of club membership has also been controlled for, because we assume that those individuals who are members of a club have a wider social network, and it might be easier for them to find a partner. Therefore, they are likely to enter a union earlier.

The relation between satisfaction and drop-out from education has already been shown in the past (Bean, 1980; Bean, 1983; Bean, 1985; Spady, 1970; Tinto, 1975). We assume that higher levels of satisfaction are associated with prolonged school enrolment. In particular, we expect the level of satisfaction with studying to have a high impact on the individual decision to exit from the educational system. Those who are more satisfied are likely to invest more in their educational career, while those who are not satisfied are more likely to quit the educational system in order to find a way of self-realisation in an alternative activity.

We assume that the transitions to first union and to education completion are highly influenced by some characteristics of the family of origin (Alwin and Thornton, 1984; Ermisch and Francesconi, 2000), because in Italy and Spain decisions about these two processes are developed while the individual is still living with the parents (Miret-Gamundi, 1997; Ongaro, 2001). Therefore, parents can influence the decision process through psychological, motivational and financial support. In particular we control for the effect of the household income, of the parents' educational level, and of the number of individuals per room in the home, considered as a proxy of the quality of life in the household.

We expect that household income effect the timing of union formation in two possible ways. On the one hand, we might assume that household income delays the entry into marriage (Goldsheider and Waite, 1986; Avery et al., 1992). We argue that individuals decide to enter into first union when they are able to form a new household as wealthy as the one they came from (Crimmins et al., 1991; Easterlin, 1987: Ch-2). This implies that people living in richer households will take longer to get sufficient financial resources to form a new wealthy household. Those individuals who are living in a poorer household might be more motivated to be independent and enter the first union, because the disadvantages of leaving the household of origin would be lower. When considering household income as a proxy of family social class, 
empirical evidence shows that women belonging to families of lower class marry early (Blossfeld and Huinink, 1991).

On the other hand, individuals highly family oriented and living in wealthy households might rely on their parents' financial support in order to form a new household. This would imply that individuals belonging to richer households are more likely to enter a union earlier (Baizan, 2001).

Concerning the effect of income on school enrolment, we expect that individuals living in richer households are likely to prolong their educational enrolment, because they can rely on financial support from their parents (Ermisch and Francesconi, 2000). In the literature a positive relationship has been shown between family social status and educational level. It interprets social status as being a proxy for the resources available to invest in the education of children (Blossfeld and Huinink, 1991; Alwin and Thonton, 1984). If we measure directly the amount of resources per individual in the household, we can expect that the higher the amount of such resources, the longer is the enrolment in school.

The parental level of education, if high, might delay the entry into first union and the exit from the educational system for students, because highly educated parents might favour investing more in their sons' and daughters' educational careers, and they might also motivate their daughters and sons to invest more in their own educational careers (Ermisch and Francesconi, 2000; Behrman et al., 1999; Billari and Ongaro, 1999; Goldsheider and Waite, 1986). Therefore, students might also delay entry into a union because they are involved in a longer education process.

Finally, the number of persons per room is controlled for. Traditionally, the effect of family size is analysed. There exists empirical evidence showing that individuals living in large households end their educational career earlier (Alwin and Thornton, 1984; Sander, 1991), enter the first union earlier (Billari and Ongaro, 1999), or leave the parental home earlier (Ongaro, 2001). This relationship might be interpreted in terms of resources available per individual in the household. Given that we measure such a variable directly, we use family size relative to the number of rooms existing at home in order to propose a measure of how much "space" each individual has. We expect that overcrowded accommodations might push young individuals out of the households of origin, in order to gain more space and independence. Thus we expect that individuals who are living in accommodations where the number of persons per room is high are more likely to end the educational process in order to enter the labour market and quickly acquire the economic independence they need to leave home. Similarly we expect, that such individuals are also more likely to enter a union early because the costs of establishing a new home are lower. Such an explanatory variable is not present in the literature. 


\section{Results}

Tables 2 and 3 illustrate parameter estimates for Italy and Spain respectively. In both cases, we estimate four different models. In model A only individual specific variables are included. In model B characteristics of the family of origin are added. Finally, in model C and D we include the same covariates used in model A and B respectively, but we add the (potentially) correlated heterogeneity terms. The value of the BIC test is included in order to give a measure of quality to the models.

These four models have been selected for two main reasons. Firstly, we would like to estimate the different effects of individual specific characteristics and of household specific characteristics. Secondly, we would like to test the presence of correlated unobserved characteristics once observed characteristics are taken into account. In sections 5.1 and 5.2 the Italian results are discussed first, and then we compare the Spanish estimates. In section 5.3 the results of simultaneous modelling are discussed at the same time for both countries. Finally in section 5.4 models according to gender are shown.

\subsection{The effect of individual specific characteristics}

In order to model entry into first union (Table 2, model A) we take into account the following individual characteristics: age, sex, highest level of education completed at the first interview, exit from the educational system, level of satisfaction with the amount of leisure time, and club membership.

Respondents are aged 17-35. The parameters of the age are significantly positive. Therefore, the higher the age, the higher the probability of entry into first union. Men enter a union significantly later than women, as already shown in the literature (Righi, 1997; Castiglioni, 1999; De Sandre et al., 2000). A high level of completed education results in a high probability of union formation. Human capital investment seems not to delay or prevent the process of union formation (Becker, 1991, supplement to ch.II) but to accelerate it. Possibly the advantages associated with higher educational levels when they enter the labour market, or higher self esteem in their ability to reach a good economic position quickly, can explain why respondents married earlier (Oppenheimer, 1988). Moreover, such a result is consistent with the findings of Marini (1984c), who showed that individuals who attain high levels of education are more likely to enter adult roles prior the completion of education because a protracted course of education increases the probability that adult roles will be entered before the completion of schooling. Thus, individuals with a higher level of education are more likely to enter a union even if their education is not finished. 
Exiting from the educational system (Table 2, model A) has a strong and significant effect on the process of first union formation. Indeed the probability of entering a union is much higher when the individual has finished education (Blossfeld and Huinink, 1991; Blossfeld and De Rose, 1992). The assumption that a standard sequence between the two events is common seems to be supported by these results.

The level of satisfaction with leisure time has an insignificant and almost neutral effect. Club membership, although insignificant, increases the probability of entering a union, possibly because of a larger social network, which can enhance the mating process. The effects of other variables, such as the level of financial satisfaction and the housing situation have been tested, but found to be insignificant in the two countries. Thus they have been excluded from the model.

Concerning exit from education, the covariates used in the model are age, sex and the level of satisfaction with the main activity, which in this case is education itself. According to age there is a clear path; rates of exit from the educational system are higher between the ages of 16 and 19 and after 25. That is to say, people are more likely to end education during high school and after the university degree. Once they have finished high school and decided to attend university, they have a lower probability to end education.

It is important to notice that there are no significant gender differences in the process, suggesting that currently there is close similarity between men's and women's participation in the educational system (Eurostat, 1997).

Individuals who are highly satisfied with the time spent studying are less likely to end education. Therefore individual attitudes play an important role, beyond other practical or economic reasons that could cause people to start working instead of going on studying. Such a variable may also be considered as a proxy for the quality of their results in school. Indeed, individuals who achieve better results studying are more likely to be satisfied with their activity. Therefore, we can assume that those who get better results prolong their educational career.

The effect of entry into union on this process has been examined. However, the low number of first union events during education precludes any estimation to this effect. This result confirms that in Italy almost nobody marries if the educational career is not completed.

The results obtained for Spain are similar to those just shown for Italy.

Concerning union formation (Table 3, model A), exit from education increases the probability of entering a union even more so in Spain than in Italy. Also gender differences in the timing of union formation are more evident in Spain than in Italy, and again we see that men form the first union later than women. The Spanish parameter of the educational level is similar to the one estimated for Italy. Therefore, also Spanish individuals with a higher educational level are more likely to enter a union early. Club membership is not significant, whereas the level of satisfaction with the amount of leisure time plays an important role. Indeed, those who are more satisfied marry much later. It is worth to underline that this covariate was not important 
in determining the process of union formation in Italy. This can be considered as a peculiarity of the Spanish model, and a symbol of how Spanish attitudes and value orientation affect the timing of union formation. Thus, leisure time is considered a commodity that somehow can be lost when a union is formed, or a way of self-realisation that lowers the need for a stable and formal relationship.

A trend suggests increased exit from the educational system with age after age 19. The level of satisfaction for time spent studying delays the exit from the educational system. The effect of the entry into first union cannot be estimated, suggesting that also Spaniards do not enter a union before they have completed their educational career.

\subsection{The effects of household specific characteristics}

Several household characteristics have important effects on both processes (Table 2, model B). Household income for instance has a significant effect on entry into union. The effect of the covariate is represented through a linear spline with a node close to the mean level of the income in the sample (Figure 1). If the income is lower than the mean, individuals are less likely to enter a union. After the node point there is a higher probability of entering a union. Possibly, , individuals need to rely on financial support from home in order to bear the costs of forming a new family while still being students . Other characteristics, such as the educational level of parents, the size of the family, or the quality of accommodation, do not influence the process of union formation.

In contrast, the exit from the educational system is influenced by a higher number of household characteristics. For instance, if the father is highly educated, the individual is likely to delay the end of the educational career. Also the effect of the mother's education, or of the mean level of parents' education, have been tested. But the father's education appears to have the clearest and strongest effect on the process. We will show later that this is true also for Spain. This is not surprising in these cultures where the father traditionally plays the role of the head of the household and where therefore many family decisions depend on him.

High household income, even if not significant, delays the exit from the educational system, suggesting that wealthy households invest more resources to lengthen their children's education.

Finally, an indicator of the quality of life in the home has been constructed, dividing the number of family components by the number of the rooms in the house (excluding the kitchen). The higher the density, the higher the probability of ending education. This result suggests that when individuals do not have enough "space" in their family of origin, they end education, probably because they feel a higher desire for independence. Still, being employed as opposed to 
being a student can be more useful in order to acquire the means to leave the family of origin and be independent.

The values of the BIC for both models (Table 2, model A and B) show that the model is significantly improved if household characteristics are included. Both processes, indeed, contribute to the transition from childhood to adulthood, which is partly determined by the family of origin.

Household characteristics affect the processes in Spain similarly to what is shown for Italy (Table 3, model B). Household income, if higher than the mean, significantly increases the probability of an individual entering a union, confirming that parental financial support allows individuals to enter a union earlier. In contrast, household income significantly decreases the probability of leaving the educational system, showing that financial support also guarantees the possibility of prolonging the educational career.

Individuals who live in a household with a high number of people per room have a higher rate of ending school. Finally, the father's educational level, when high, delays the end of schooling, but affects Spaniards to a lesser extent than Italians.

In the case of Spain, the use of household characteristics does not improve the explanation of the processes (Tab. 3, BIC for model A and B).

\subsection{Simultaneous models}

Models $\mathrm{C}$ and D (Table 2 and 3) show the estimates when the heterogeneity terms and the correlation between them is included.

Firstly, in both countries there is a high and significant correlation between the unobserved characteristics that influence the first union formation process and the end of the educational career. This means that individuals who, for "any unobserved reason", are likely to marry early, are simultaneously likely to end school early. We suggest interpreting this feature in terms of individuals' value orientations and attitudes.

Family oriented individuals are more likely to complete their educational careers early because in this way they can more easily enter other family roles such as being married and being parents. Indeed, as discussed before, individuals may decide to end education in order to achieve a stable economic position sooner and (especially men), making the union formation easier, or they can decide to specialise in household activities that increase the gain from marriage (especially women). On the other hand career-oriented individuals are likely to invest more in their educational career first, and job career later, and they are less likely to leave room for early union formation. 
Controlling for the endogeneity of the processes, the effect of educational career completion on first union formation is reduced. In fact, the exit from education still strongly increases the risk of entering a union, but much less so than what is observed when the two processes are treated independently. In other words, if endogeneity is not controlled for, the effect of educational enrolment is overestimated. This is true also for the effect of the educational level. This implies that if first union and education career are not modelled simultaneously, the estimates of the educational effects can be highly biased.

It is worth noting that the estimates of covariates and correlation terms are also stable when different values of the variance terms $\left(\sigma_{u}^{2}\right.$ and $\left.\sigma_{e}^{2}\right)$ are used (not documented here). As argued in section 4.2 we use the BIC values for compare non-nested models. They show that controlling for the endogeneity of the processes improves the model considerably (Table 2 and 3).

\subsection{Gender differences}

The results shown up to now suggest that in Italy and Spain union formation and the exit from education affect each other in the same way, and that each process is influenced almost identically by the same set of covariates. This allows for a pooling of the Italian and Spanish data-sets in order to model separately by gender, and to at the same time control for the existence of gender differences in the effect of the covariates on union formation and the timing of exit from education.

Table 4 shows the parameters of the models' estimates for the two countries and the two sexes together (model C and D), and for the two countries together but for women only (model $\mathrm{CW}$ and DW). From the comparison between the first two and the last two models, the resulting existence of gender differences can be outlined ${ }^{3}$.

Models show that there are gender differences but no country differences in the timing of first union formation: Men marry later than women in the same proportion in both countries. On the other hand, there are no gender differences in the timing of exit from education, but there are strong and significant differences between the two countries. Indeed, Spaniards exit from the education system much earlier than Italians. This could be partly due to the differences in the education systems of the two countries. In fact in Spain finishing high school and university should take place at an earlier age than in Italy.

Concerning the covariates' effects on union formation, we notice that after leaving school women face a greater risk of entering a union than men (Corijn, 2001). The educational level,

\footnotetext{
${ }^{3}$ We are not able to estimate directly the models for men only, because the occurrence of too few events of first union for men during the period of observation.
} 
has a lower (and less significant) impact on women, suggesting that high educational levels improve men's marriage chances more than it does women's. Finally, household income is less significant in determining the timing of women's union formation. This is probably the case because the responsibility of supporting of the new household financially traditionally rests on men.

The effects of household characteristics on exit from education are not highly gender differentiated. Income is less significant in determining the exit from education for women than it is for men, while the number of individuals per room in the accommodation has a stronger effect on women. This would imply that women suffer from the consequences of overcrowded accommodation more than men.

Finally, it is worth underlining that those gender differences, that have been observed, concern the significance and the intensity of the effect of the covariates, but never the sign of the estimates. Therefore, we can conclude that there are no important gender differences in the way the processes are influenced by other variables and in their mutual relations.

\section{Conclusions}

In this paper, we have focused on the processes of first union formation and exit from education, on their causal interrelationship, and on the existence of unobservable factors influencing both processes simultaneously. The main assumption is that these two processes represent interrelated trajectories in the course of an individual's life. Therefore, choices made in one process limit the freedom to choose in others (Blossfeld and Huinink, 1991; Hoem, 1986; David and Bumpass, 1976; McLaughlin et al., 1986). Decision-making attributes are developed according to both individual and household characteristics, given that both processes are collocated in the stage of the life between childhood and adulthood, when the influence of the family of origin is still important (Goldscheider and Waite, 1986; Alwin and Thornton, 1984; Ermisch and Francesconi, 2000). Moreover, we assume that there could be individual unobserved characteristics that influence simultaneously entry into union and the end of education (Boulier and Rosenzweig, 1984; Sander, 1992; Lillard et al., 1994).

These processes are analysed in the particular cultural context of Italy and Spain, both of which are characterised by an increasing postponement of the transition to adulthood (Ongaro, 2001; Baizan, 2001). Consequently, the dynamics of these two processes are particularly relevant. Both countries are experiencing several economic and demographic trends in a similar way (Delgado and Castro Martin, 1999; De Sandre et al., 2000). Therefore the assumption is that the processes of union formation and exit from education, plus their mutual relations and determinants are not dissimilar in Italy and Spain. 
Results show that both processes are influenced by individual and household characteristics. In particular, first union is more likely to be formed when the individual has finished the educational career, and has a high level of education. Also, club membership enhances the chances of entering into the first union, while being satisfied with the amount of leisure time delays the transition to married status. People living in high income households are more likely to marry. In the case of exit from education, it is postponed if the individual has a high level of satisfaction with studying. Household characteristics affect this process more than the other criteria. Indeed household income, the father's education, and the quality of accommodation effect the educational career. In particular, the higher the household income, and the higher the father's education, the longer a student stays enrolled. However, when the accommodation is characterised by a high number of people per room, the individual is more likely to drop out from school early.

Union formation is characterised by a strong gender difference in Italy and Spain, because men marry significantly later than women. In contrast, educational careers appear not to be differentiated by gender. Also the effect of the individual and household characteristics on the processes are fairly similar for both genders .

After showing that education affects union formation, a further analysis has been developed in order to control for the unobservable characteristics that could potentially effect both processes simultaneously. The processes certainly appear to be endogenous in the sense that they are influenced in the same direction by unobserved individual characteristics which in this paper are interpreted, in terms of value orientations and attitudes. Family oriented individuals are more likely to both enter the first union, and end education early. In contrast, individuals who find a way of self-realisation in the educational career, are less likely to exit from the educational system. They are also less likely to enter a union, possibly because they may try to invest more in their professional careers, after having made high investments in their educational careers.

The endogeneity of the processes is also relevant because if it is not controlled for, the effects of education enrolment and educational level on union formation are overestimated. Therefore, when modelling union formation it is necessary to model education as an endogenous process to achieve unbiased results.

Using this data set for these analyses represents certain novelties. In fact, data are recent and rich in information about individual and household characteristics covering demographic, social, and economic aspects. These are important when the dynamics and the interrelationships among the different trajectories in individual lives are to be analysed. It is worthy indeed, to control for how the direct environment (the household) surrounding the individual influences his or her decision making process psychologically and practically. In addition, changes reflecting household conditions and other aspects in individual lives are collected simultaneously, simplifying the interpretation of the causal relationship among different trajectories. Finally, data 
regarding levels of satisfaction that can strongly influence individual choices are collected exactly while the process is taking place, therefore representing an important key for the interpretation of the decision making process itself.

On the other hand these same data sets have some limitations. Indeed, only five annual waves are available at the moment. This implies that individuals are observed over the course of only four years, and only few events of "first union" and "end of education" can take place during such a short period. This is true especially in Italy and Spain where the distribution of such events is spread widely over a life span.

\section{Acknowledgments}

This paper is based on analysis of the European Community Household Panel for 1994-1998. The data are used with the permission of Eurostat, who bear no responsibility for the analysis or interpretation presented here.

I would like to thank the Max Planck Institute for Demographic Research for supporting this research, and for providing such a good work environment. In particular, I would like to thank Francesco C. Billari for his advisory support, as well as Arnstein Aassve, Pau Baizan, Jan Hoem, Stefano Mazzuco and Francesca Michielin for their very useful suggestions and comments.

\section{Annex: extracting the data from the ECHP}

In this paper we present the results of the simultaneous modelling of the processes of entry into first union and definitive exit from the educational system, through a system of two continuos hazard equations. Therefore, only those individuals who were in education, never married and not in consensual union at the first interview are selected for the analysis. Individuals are followed up during the four years under observation. If they are not interviewed in one of the years of the survey, they are considered as censored from the last interview available onwards.

The dependent variables of the two hazard models are the time at first union and the time at exit from education. The ECHP does not provide exact dates of when the entry into first union and the definitive exit from the educational took place, and thus we had to reconstruct them. In this section we provide a detailed description of the reconstruction of the dependent variables. 


\section{a. entry into first union}

Firstly, individuals were selected who were never married and not in a consensual union at the time of the first interview. Then, for those individuals who from one wave to the following changed their marital status (from never married to married- PD005) or entered a consensual union (PD007), the date of entry into union was reconstructed according to the available information.

For married individuals the year of marriage is available (PD006), but not the month. In order to know the month the marriage took place, we made some assumptions according to the migration trajectory of the individual:

- for individuals who moved out from the original household at the time of marriage, the month the move to a new address occurred was assigned (HA001 and HA002).

When such information was missing, instead of reconstructing the exact date of entry into union, the interval of time during which the event took place was reconstructed.

If the year of the marriage was before the year of the current interview, then the range of such interval is between the date (month and year PG006 and PG007) of the previous interview and December of the year of marriage. If the year of marriage is the same as that of the current interview, then the range of the interval is between January of the year of marriage and the date of the current interview (month and year). If also the year of marriage is missing, then the range of the interval varies between the dates of the two contiguous interviews.

- for individuals who did not move out from the original household after the first marriage, the month the spouse moved to his or her household was assigned (PIO_YYi and PIO_MMi). If such information was missing, an interval in which the event took place was reconstructed, as described above.

\section{b. definitive exit from education}

The ECHP provides a calendar of monthly main activities during the year previous to the interview (PC001-PC012). According to this information, we selected individuals who were studying (as their main activity) during the month of the interview. For these individuals we know month by month whether they were studying or not. We assume that the exit from education is definitive when the individual is out of the educational system for more than 5 months in a row. In this way, we consider as full time students those individuals who would interrupt their studies for summer holidays or other such reasons that do no concern the free choice to leave the education system. Nevertheless, there are some (few) cases in which 
individuals re-enter the educational system after having been away from it for more than 5 months. We disregard such entries because we assume that they are the result of a choice determined by a mismatch between the individual's expectations and the reality out of the educational system. An example would be somebody who decided to stop studying in order to start working. If he or she did not find a job, he or she could be motivated to re-enter the educational system.

Concerning men only, we made a further assumption for those involved in military service. We assume that some individuals had to interrupt their studies not according to free choice, but to participate in military service, which was compulsory in both countries during the years for which the survey is available. So those individuals who re-entered the educational system over a period shorter than 5 months after military service was completed, are considered as continuously in education.

The monthly calendar of activities provides detailed information until December of the year previous to the last interview. Therefore, the participation in the education system in the period between January of the year of the last interview and the month of the last interview must be reconstructed according to other information. The individual is considered continuously in education since January to the finishing month of the last educational course (PT006-PT011), if the individual is not in education at the last interview. Otherwise, if the individual is still in education at the interview, he or she is considered as continuously in education since January until the month of the last interview. 


\section{References}

Akerlof G. A., Rose A. K, and Yellen J. L. (1988) Job Switch and Job Satisfaction in the U. S. Labour Market, Brookings Papers on Economic Activity, Volume 1988 (2): 495-582

Alexander, K. L. and Reilly, T. W. (1981) Estimating the Effect of Marriage Timing on Educational Attainment: Some Procedural Issues and Substantive Clarifications, American Journal of Sociology, 87: 143-156

Alwin D. F. and Thornton A. (1984) Family Origins and the Schooling Process: Early versus Late Influence of Parental Characteristics, American Sociological Review, 49: 784-802

Avery R., Goldsheider F., and Speare A. Jr. (1992) Feathered Nest/Gilded Cage: Parental Income and Leaving Home in the Transition to Adulthood, Demography, 29(3): 375-388

Baizan, P. (2001) Transition to Adulthood in Spain, in Corijn M and Klijzing (eds.), Transition to Adulthood in Europe, Dordrecht, The Netherlands, Kluwer Acadmic Publisher: 279-311

Bean J. P. (1980) The Synthesis of a Causal Model of Student Attrition, Research in Higher Education, 12: 155-187

Bean J. P. (1983) The Application of a Model of Turnover Organisations to the Student Attrition Process, The Review of Higher Education, 2: 129-148

Bean J. P. (1985) Interaction Effects Based on Class Level in an Explanatory Model of College Student Dropout Syndrome, American Educational Research Journal, 22: 35-64

Becker, G. S. (1973) A Theory of Marriage: Part I, The Journal of Political Economy, 81: 813846

Becker, G. S. (1991) A Treatise on the Family, Cambridge, Harvard University Press

Behrman J. R., Foster A. D., Rosenzweig M. R., and Vashishtha P. (1999) Women's Schooling, Home Teaching, and Economic Growth, Journal of Political Economy, 107(4): 682-714

Billari, F. C. and Ongaro, F. (1999) Lasciare la Famiglia di Origine: Quando e Perché?, in De Sandre P., Pinnelli A., and Santini A, Nuzialità e Fecondità in Trasformazione: Percorsi e Fattori di Cambiamento, Bologna, Il Mulino: 327-346

Billari, F. C. and Micheli, G. A. (2001) Social Norms and Demographic Events in Contemporary Westerns Societies: Can We Learn from Southern Europe?, mimeo, Max Planck Institute, Rostock

Billari F. C., Castiglioni M., Castro Martìn T., Michielin F. and Ongaro F. (forthcoming), Household and Union Formation in a Mediterranean Fashion: Italy and Spain, in E. Klijzing and M. Corijn (Eds.), Comparative Research on Fertility and the Family in Contemporary Europe: Findings and Lessons, New York/Geneva, United Nations

Blossfeld, H. P. and Huinink, J. (1991) Human Capital Investments or Norms of Role Transition? How Women's Schooling and Career Affect the Process of Family Formation, American Journal of Sociology, 97: 143-168

Blossfeld, H. P. and De Rose, A. (1992) Educational Expansion and Changes in Entry into Marriage and Motherhood. The Experience of Italian Women, Genus, 48: 73-89 
Blossfeld, H. P. and Rower, G. (1995) Techniques of Event History Modelling, Mahwah, NJ, Lawrence Erlbaum Associates

Boulier, B. L. and Rosenzweig, M. R. (1984) Schooling, Search and Spouse Selection: Testing Economic Theories of Marriage and Household Behaviour, The Journal of Political Economy, 92: $712-732$

Broman C. L. (1988) Satisfaction among Blacks: the Significance of Marriage and Parenthood, Journal of Marriage and the Family, 50(1): 45-51

Castiglioni, M. (1999) Analisi Differenziale di Nuzialità, in De Sandre P., Pinnelli A., and Santini A (Eds), Nuzialità e Fecondità in Trasformazione: Percorsi e Fattori di Cambiamento, Bologna, Il Mulino: 347-363

Castro Martin, T. (1993) Changing Nuptiality Patterns in Contemporary Spain, Genus, 49: 79-95

Clarkberg, M. (1999) The Price of Partnering: The Role of Economic Well-Being in Young Adults' First Union Experiences, Social Forces, 77: 945-968

Corijn M (2001) Transition to adulthood: sociodemographic factors, in Corijn M. and Klijing E. (Eds.), Transition to Adulthood in Europe, Kluwer Academic Publisher, Dordrecht, The Netherlands

Crimmins E. M., Easterlin R. A., and Saito Y. (1991) Preferences Changes among American Youth: Family, Work, and Goods Aspirations, 1976-86, Population and Development Review, 17(1): 115-133

Davis, J. N. and Bummpass, L. L. (1976) The Continuation of Education after Marriage among Women in the United States: 1970, Demography, 13: 161-174

Delgado, M. and Castro Martin, T. (1999) Family and Fertility Surveys in Countries of the ECE Region. Standard Country Report. Spain, Geneva, United Nations

De Sandre, P. (1997) La Formazione di Nuove Famiglie, in Barbagli, M. and Saraceno, C. (eds.), Lo Stato delle Famiglie in Italia, Bologna, Il Mulino: 65-75

De Sandre, P. and Ongaro, F. and Rettaroli, R. and Salvini, S. (2000) Fertility and Family Surveys in Countries of the ECE Region. Standard Country Report. Italy, Geneva, United Nations

Easterlin R. A. (1987) The Impact of Numbers on Personal Welfare, Chicago, University of Chicago Press

Esping-Andersen G. (1999) Social Foundations of Postindustrial Economies, Oxford: Oxford University Press

Ermisch J and Francesconi M (2000) Educational Choice, Families and Young People's Earnings, The Journal of Human Resources, 35(1): 143-176

Eurostat (1997) Yearbook '97, Eurostat

Eurostat (2000) European Social Statistics. Demography, Eurostat 
Eurostat (2001), ECHP UDB Manual. European Community Household Panel Longitudinal Users' Database, Eurostat

Freeman R. B. (1978) Job Satisfaction as an Economic Variable, The American Economic Review, 68(2): 135-141

Goldscheider, F. K. and Waite, L. J. (1986) Sex Differences in the Entry into Marriage, American Journal of Sociology, 92: 91-109

Gonzalez, M. J. (2000) Partnership Formation in the Context of Women's Growing Educational Attainment, Working Paper 180, Centre d'Estudis Demografics, Barcelona

Hoem, J. M. (1986) The Impact of Education on Modern Family-Union Initiation, European Journal of Population, 2: 113-133

Istat (2001) La Situazione Economica e Finanziaria delle Famiglie in Italia e in Europa, Informazioni n.11

Jansen, M. and Kalmijn, M. (2002) Investment in Family Life: the Impact of Value Orientations on Patterns of Consumption, Production and Reproduction in Married and Cohabiting Couples, in Lesthaeghe, R. (Ed.) Meaning and choice: Value orientations and lifecourse decisions, NIDI CBGS Publications nr. 37: 129-169

Kohler H. P., Ortega J. A., and Billari F. C. (2001), Towards a Theory of Lowest-Low Fertility, MPIDR Working Paper WP-2001-032, Max Plank Institute, Rostock, (forthcoming, pending revisions, at Population and Development Review)

Landale N. S. and Guest A. M. (1985) Constraints, Satisfaction and Residential Mobility: Speare's Model Reconsidered, Demography, 22(2):199-222

Lesthaeghe R. and Surkyn J. (1988) Cultural Dynamics and Economic Theories on Fertility Change, Population and Development Review, 14: 1-45

Lesthaeghe R. and Moors G. (1995) Is there a New Conservatism that Will Bring Back the Old Family?, in Evolution or Revolution in European Populations, European Population Conference, Milan, EAPS-IUSSP: 225-266

Lesthaeghe R., and Vanderhoeft C. (1977) Ready, Willing and Able. A Conceptualization of Transitions to New Behavioural Forms, Interuniversity Papers in Demography, IPD Working Paper 1977-8, Brussels, Free University Brussels

Liebroef A. C. and Corijn M. (1999) Who, What, Where, and When? Specifying the Impact of Educational Attainment and Labour Force Participation on Family Formation, European Journal of Population, 15: 45-75

Lillard, L. A. (1993), Simultaneous Equations for Hazards: Marriage Duration and Fertility Timing, Journal of Econometrics, 56: 189-217

Lillard, L. A. and Panis, C. W. A. and Upchurch, D. M. (1994) Interdependencies Over the Life Course: Women's Fertility, Marital, and Educational Experiences, RAND Working Paper 94-17, Santa Monica, CA.

Lillard, L. A. and Panis, C. W. A. (2000) aML Multilevel Multiprocess Statistical Software, Release 1.0, Los Angeles, California, EconWare 
Marini, M. M. (1978) The Transition to Adulthood: Sex Differences in Educational Attainment and Age at Marriage, American Sociological Review, 43: 483-507

Marini, M. M. (1984) Age and Sequencing Norms in the Transition to Adulthood, Social Forces, 63: $229-244$

Marini, M. M. (1984b) Women's Educational Attainment and the Timing of Entry into Parenthood, American Sociological Review, 49: 491-511

Marini, M. M. (1984c) The Order of Events in the Transition to Adulthood, Sociology of Education, 57: 63-84

McLaughlin S. D. and Grady, W. R. and Billy, J. O. G. and Landale, N. S. and Winges L. D. (1986) The Effect of the Sequencing of Marriage and First Birth During Adolescence, Family Planning Perspective, 18: 12-18

Miret Gamundi P. (1997) Nuptiality Patterns in Spain in the Eighties, Genus 53: 183-198

Morris E. W., Crull S. R., and Winter M. (1976) Housing Norms, Housing Satisfaction and the Propensity to Move, Journal of Marriage and the Family, 38(2): 309-320

Ongaro, F. (2001) Transition to Adulthood in Italy, in Corijn M and Klijzing (eds.), Transition to Adulthood in Europe, Dordrecht, The Netherlands, Kluwer Acadmic Publisher: 173-208

Oppenheimer, V. K. (1988) A Theory of Marriage Timing, American Journal of Sociology, 94: $563-591$

Oppenheimer, V. K. (1994) Women's Rising Employment and the Future of the Family in Industrial Societies, Population and Development Review, 20: 293-342

Raftery, A. E. (1995) Bayesian Model Selection in Social Research, Sociological Methodology, 25: $111-163$

Reher D. S. (1998) Family Ties in Western Europe: Persistent Contrasts, Population and Development Review, 24: 203-234

Righi, A. (1997) La Nuzialità, in Barbagli, M. and Saraceno, C. (eds.), Lo Stato delle Famiglie in Italia, Bologna, Il Mulino: 53-64

Ryan J. (1981) Marital Status, Happiness, and Anomia, Journal of Marriage and the Family, 43(3): 643-649

Sabbadini, L. L. (1997) Le Convivenze "More Uxorio", in Barbagli, M. and Saraceno, C. (eds.), Lo Stato delle Famiglie in Italia, Bologna, Il Mulino: 86-94

Sander, S. (1992) Unobserved Variables and Marital Status, Journal of Population Economics, 5: 217-228

Spady W. (1970) Dropouts from Higher Education: an Interdisciplinary Review and Synthesis, Interchange, 1: 64-85

Speare A. Jr. (1974) Residential Satisfaction as an Intervening Variable in Residential Mobility, Demography, 11(2): 173-188 
Stack S. and Eshleman J. R. (1998) Marital Status and Happiness: a 17-Nation Study, Journal of Marriage and the Family, 60(2): 527-536

Teachman, J. D. and Polonko, K. A. (1988) Marriage, Parenthood, and the College Enrolment of Men and Women, Social Forces, 67: 512-523

Thornton, A. and Axinn, W. G and Teachman, J. D. (1995) The Influence of School Enrolment and Accumulation on Cohabitation and Marriage in Early Adulthood, American Sociological Review, 60: 762-774

Tinto V. (1975) Dropout from Higher Education: a Theoretical Synthesis of Recent Research, Research in Higher Education, 45: 89-125

Tobio, C. (2001) Marriage, Cohabitation and the Residential Independence of Young People in Spain, International Journal of Law, Policy and the Family, 15: 68-87

Upchurch, D. M. and Mc Carty J. (1990) The Timing of a First Birth and High School Completion, American Sociological Review, 55: 224-234

Upchurch, D. M. and Lillard, L. A. and Panis, C. W. A.. (2001) The Impact of Nonmarital Childbearing on Subsequent Marital Formation and Dissolution, in Lawrence Wu and Barbara Wolfe(Eds), Out of Wedlock: Causes and Consequences of Nonmarital Fertility, New York, Russell Sage Foundation: 344-380

Waite, L. J. and Moore, K. A. (1978) The Impact of an Early First Birth on Young Women's Educational Attainment, Social Forces, 56: 845-865 
Tables

Table 1: Number of individuals and events by country and gender

\begin{tabular}{cccc}
\hline & $\begin{array}{c}\text { Events } \\
\text { "first union" }\end{array}$ & $\begin{array}{c}\text { Events } \\
\text { "exit from education" }\end{array}$ & $\begin{array}{c}\text { Total } \\
\text { individuals }\end{array}$ \\
\hline Italy & & & \\
Women & 58 & 346 & 637 \\
Men & 27 & 347 & 710 \\
Total & 85 & 693 & 1347 \\
Spain & & & \\
Women & 50 & 357 & 515 \\
Men & 12 & 281 & 621 \\
Total & 62 & 638 & 1136 \\
\hline
\end{tabular}

Figure 1: The effect of household income by country

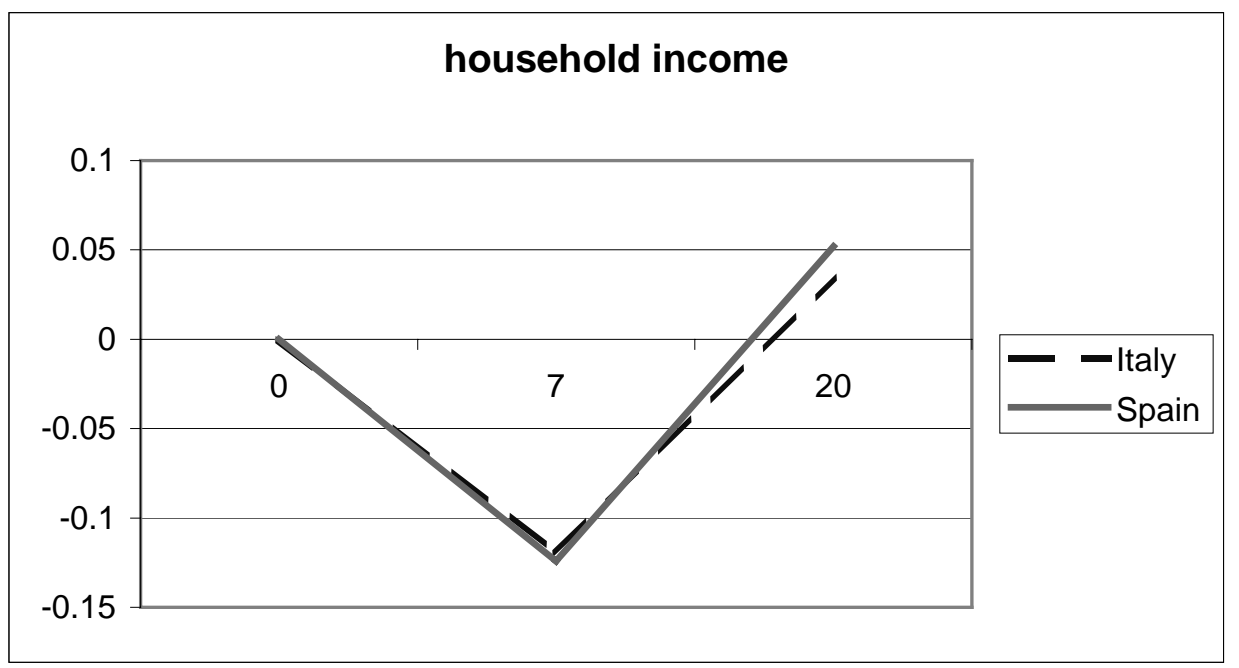


Table 2: Results of models for Italy

\begin{tabular}{|c|c|c|c|c|c|c|c|c|}
\hline \multirow[b]{2}{*}{ First Union } & \multicolumn{2}{|c|}{ Model A } & \multicolumn{2}{|c|}{ Model B } & \multicolumn{2}{|c|}{ Model C } & \multicolumn{2}{|c|}{ Model D } \\
\hline & par. & s.e. & par. & s.e. & par. & s.e. & par. & s.e. \\
\hline Constant & -7.264 & $0.856 * * *$ & -6.662 & $0.897 * * *$ & -7.610 & $0.918 * * *$ & -6.938 & $0.959 * * *$ \\
\hline 16-24 years old (linear spline) & 0.445 & $0.119 * * *$ & 0.438 & $0.120 * * *$ & 0.424 & $0.127 * * *$ & 0.422 & $0.129 * * *$ \\
\hline More than 24 years old (linear spline) & 0.142 & $0.039 * * *$ & 0.143 & $0.041 * * *$ & 0.194 & $0.049 * * *$ & 0.196 & $0.051 * * *$ \\
\hline Men & -0.836 & $0.249 * * *$ & -0.803 & $0.251 * * *$ & -0.994 & $0.292 * * *$ & -0.992 & $0.297 * * *$ \\
\hline Exited from education & 1.779 & $0.499 * * *$ & 1.754 & $0.499 * * *$ & 1.255 & $0.576 * * *$ & 1.255 & $0.575 * * *$ \\
\hline University degree & 0.778 & $0.310 * *$ & 0.785 & $0.313 * *$ & 0.720 & $0.405 * *$ & 0.724 & $0.422 *$ \\
\hline Satisfaction with leisure time & 0.012 & 0.089 & 0.009 & 0.092 & -0.028 & 0.102 & -0.042 & 0.107 \\
\hline Member of a club & 0.351 & 0.259 & 0.344 & 0.262 & 0.467 & $0.312 *$ & 0.460 & 0.318 \\
\hline Income lower than mean (linear spline) & & & -0.120 & $0.059 * *$ & & & -0.134 & $0.069 * *$ \\
\hline Income higher than mean (linear spline) & & & 0.035 & $0.014 *$ & & & 0.037 & 0.019 \\
\hline \multicolumn{9}{|l|}{ Out of Education } \\
\hline Constant & -2.631 & $0.402 * * *$ & -2.812 & $0.433 * * *$ & -4.048 & $0.457 * * *$ & -4.411 & $0.516 * * *$ \\
\hline 16-19 years old (linear spline) & 0.528 & $0.141 * * *$ & 0.549 & $0.142 * * *$ & 0.999 & $0.158 * * *$ & 1.031 & $0.159 * * *$ \\
\hline 19-25 years old (linear spline) & -0.072 & $0.020 * * *$ & -0.067 & $0.020 * * *$ & -0.069 & $0.028 * *$ & -0.057 & $0.028 * *$ \\
\hline More than 25 years old (linear spline) & 0.172 & $0.016 * * *$ & 0.169 & $0.015 * * *$ & 0.267 & $0.032 * * *$ & 0.271 & $0.032 * * *$ \\
\hline Men & 0.121 & 0.071 & 0.146 & $0.071 *$ & 0.107 & 0.112 & 0.149 & 0.112 \\
\hline Satisfaction with studying & -0.132 & $0.023 * * *$ & -0.121 & $0.023 * * *$ & -0.180 & $0.037 * * *$ & -0.157 & $0.037 * * *$ \\
\hline Income & & & -0.012 & 0.009 & & & -0.017 & 0.012 \\
\hline Father's educational level & & & -0.612 & $0.155 * * *$ & & & -0.858 & $0.215 * * *$ \\
\hline Persons per room & & & 0.190 & $0.096 *$ & & & 0.316 & $0.153 * *$ \\
\hline Sigma union & & & & & 1.2 & & 1.2 & \\
\hline Sigma education & & & & & 1.2 & & 1.2 & \\
\hline Rho & & & & & 0.630 & $0.169 * * *$ & 0.645 & $0.175 * * *$ \\
\hline $\ln -\mathrm{L}$ & -3972.99 & & -3952.27 & & -3942.06 & & -3919.96 & \\
\hline $\mathrm{BIC}$ & -3180.56 & & -3189.07 & & -3235.83 & & -3247.11 & \\
\hline
\end{tabular}

Significance: $*=10 \% ; * *=5 \% ; * * *=1 \%$. 
Table 3: Results of models for Spain

\begin{tabular}{|c|c|c|c|c|c|c|c|c|}
\hline \multirow{2}{*}{ Union Formation } & \multicolumn{2}{|c|}{ Model A } & \multicolumn{2}{|c|}{ Model B } & \multicolumn{2}{|c|}{ Model C } & \multicolumn{2}{|c|}{ Model D } \\
\hline & Par. & s.e. & par. & s.e. & par. & s.e. & par. & s.e. \\
\hline Constant & -6.191 & $0.722 * * *$ & -5.645 & $0.798 * * *$ & -6.689 & $0.807 * * *$ & -6.113 & $0.922 * * *$ \\
\hline 16-24 years old (linear spline) & 0.421 & $0.100 * * *$ & 0.418 & $0.102 * * *$ & 0.416 & $0.110 * * *$ & 0.423 & $0.113 * * *$ \\
\hline more than 24 years old (linear spline) & 0.090 & 0.086 & 0.095 & $0.091 *$ & 0.148 & $0.095 * *$ & 0.148 & $0.101 * *$ \\
\hline Men & -1.280 & $0.359 * * *$ & -1.318 & $0.357 * * *$ & -1.365 & $0.389 * * *$ & -1.405 & $0.389 * * *$ \\
\hline Exit from education & 1.960 & $0.480 * * *$ & 1.904 & $0.488 * * *$ & 1.328 & $0.562 * * *$ & 1.311 & $0.564 * *$ \\
\hline University degree & 0.754 & $0.329 * * *$ & 0.816 & $0.332 * * *$ & 0.688 & $0.387 * *$ & 0.748 & $0.393 * *$ \\
\hline Satisfaction with leisure time & -0.188 & $0.091 * *$ & -0.187 & $0.094 * *$ & -0.230 & $0.107 * *$ & -0.224 & $0.110 * *$ \\
\hline Member of a club & -0.066 & 0.340 & -0.074 & 0.352 & 0.024 & 0.380 & 0.029 & 0.400 \\
\hline Income lower than mean (linear spline) & & & -0.124 & $0.071 *$ & & & -0.149 & $0.085 * *$ \\
\hline Income higher than mean (linear spline) & & & 0.052 & $0.028 * *$ & & & 0.057 & $0.034 *$ \\
\hline Out of Education & & & & & & & & \\
\hline Constant & -0.423 & 0.352 & -0.356 & 0.382 & -0.803 & $0.403 *$ & -0.728 & 0.464 \\
\hline 16-19 years old (linear spline) & -0.257 & $0.124 *$ & -0.254 & $0.125 *$ & -0.178 & 0.137 & -0.178 & 0.139 \\
\hline 19-25 years old (linear spline) & 0.191 & $0.022 * * *$ & 0.196 & $0.022 * * *$ & 0.302 & $0.030 * * *$ & 0.313 & $0.031 * * *$ \\
\hline more than 25 years old (linear spline) & 0.064 & 0.040 & 0.057 & 0.038 & 0.121 & $0.072 *$ & 0.117 & 0.069 \\
\hline Men & -0.071 & 0.073 & -0.025 & 0.074 & -0.060 & 0.115 & -0.003 & 0.116 \\
\hline Satisfaction with studying & -0.168 & $0.029 * * *$ & -0.163 & $0.029 * * *$ & -0.220 & $0.045 * * *$ & -0.213 & $0.044 * * *$ \\
\hline Income & & & -0.025 & $0.010 * *$ & & & -0.037 & $0.015 * * *$ \\
\hline Father's educational level & & & -0.222 & $0.104 *$ & & & -0.368 & $0.162 * *$ \\
\hline Persons per room & & & 0.076 & 0.117 & & & 0.149 & 0.180 \\
\hline sigma union & & & & & 1.2 & & 1.2 & \\
\hline sigma education & & & & & 1.2 & & 1.2 & \\
\hline Rho & & & & & 0.701 & $0.199 * * *$ & 0.673 & $0.198 * * *$ \\
\hline $\ln -\mathrm{L}$ & -3368.83 & & -3357.14 & & -3317.96 & & 3304.87 & \\
\hline $\mathrm{BIC}$ & -1750.75 & & -1741.37 & & -1845.94 & & -15058.8 & \\
\hline
\end{tabular}

Significance: $*=10 \% ; * *=5 \% ; * * *=1 \%$. 
Table 4: Results of models with joined countries, for both genders, and for women only

\begin{tabular}{|c|c|c|c|c|c|c|c|c|}
\hline \multirow{2}{*}{ Union Formation } & \multicolumn{2}{|c|}{ Model C } & \multicolumn{2}{|c|}{ Model D } & \multicolumn{2}{|c|}{ Model CW } & \multicolumn{2}{|c|}{ Model DW } \\
\hline & Par. & s.e. & par. & s.e. & par. & s.e. & par. & s.e. \\
\hline Constant & -7.157 & $0.601 * * *$ & -6.495 & $0.650 * * *$ & -7.081 & $0.658 * * *$ & -6.472 & $0.716 * * *$ \\
\hline 16-24 years old (linear spline) & 0.423 & $0.079 * * *$ & 0.425 & $0.080 * * *$ & 0.405 & $0.086 * * *$ & 0.409 & $0.087 * * *$ \\
\hline more than 24 years old (linear spline) & 0.178 & $0.041 * * *$ & 0.179 & $0.043 * * *$ & 0.153 & $0.053 * * *$ & 0.152 & $0.056 * * *$ \\
\hline Spain & -0.099 & 0.207 & -0.115 & 0.210 & 0.069 & 0.239 & 0.046 & 0.241 \\
\hline Men & -1.141 & $0.227 * * *$ & -1.143 & $0.230 * * *$ & & & & \\
\hline Exit from education & 1.245 & $0.392 * * *$ & 1.227 & $0.393 * * *$ & 1.493 & $0.418 * * *$ & 1.488 & $0.422 * * *$ \\
\hline University degree & 0.629 & $0.268 * *$ & 0.664 & $0.273 * * *$ & 0.483 & 0.347 & 0.525 & $0.354 *$ \\
\hline Satisfaction with leisure time & -0.114 & $0.070 *$ & -0.119 & $0.073 *$ & -0.098 & 0.086 & -0.098 & 0.089 \\
\hline Member of a club & 0.279 & 0.232 & 0.274 & 0.236 & 0.107 & 0.292 & 0.123 & 0.301 \\
\hline Income lower than mean (linear spline) & & & -0.144 & $0.051 * * *$ & & & -0.136 & $0.062 * *$ \\
\hline Income higher than mean (linear spline) & & & 0.044 & $0.016 * *$ & & & 0.035 & 0.027 \\
\hline \multicolumn{9}{|l|}{ Out of Education } \\
\hline Constant & -2.807 & $0.304 * * *$ & -3.042 & $0.348 * * *$ & -3.028 & $0.430 * * *$ & -3.384 & $0.483 * * *$ \\
\hline 16-19 years old (linear spline) & 0.458 & $0.103 * * *$ & 0.477 & $0.103 * * *$ & 0.484 & $0.146 * * *$ & 0.499 & $0.146 * * *$ \\
\hline 19-25 years old (linear spline) & 0.095 & $0.020 * * *$ & 0.109 & $0.020 * * *$ & 0.118 & $0.027 * * *$ & 0.133 & $0.028 * * *$ \\
\hline more than 25 years old (linear spline) & 0.192 & $0.030 * * *$ & 0.193 & $0.029 * * *$ & 0.179 & $0.040 * * *$ & 0.173 & $0.039 * * *$ \\
\hline Spain & 0.615 & $0.081 * * *$ & 0.661 & $0.084 * * *$ & 0.677 & $0.112 * * *$ & 0.711 & $0.115 * * *$ \\
\hline Men & 0.029 & 0.080 & 0.081 & 0.080 & & & & \\
\hline Satisfaction with studying & -0.206 & $0.028 * * *$ & -0.190 & $0.028 * * *$ & -0.188 & $0.039 * * *$ & -0.166 & $0.039 * * *$ \\
\hline Income & & & -0.025 & $0.009 * * *$ & & & -0.021 & $0.013 *$ \\
\hline Father's educational level & & & -0.549 & $0.128 * * *$ & & & -0.508 & $0.184 * * *$ \\
\hline Persons per room & & & 0.283 & $0.114 * * *$ & & & 0.359 & $0.149 * * *$ \\
\hline sigma union & & & & & 1.2 & & 1.2 & \\
\hline sigma education & & & & & 1.2 & & 1.2 & \\
\hline Rho & 0.644 & $0.135 * * *$ & 0.659 & $0.135 * * *$ & 0.655 & $0.159 * * *$ & 0.653 & $0.161 * * *$ \\
\hline $\ln -\mathrm{L}$ & -7308.07 & & -7275.06 & & -4050.98 & & -4034.89 & \\
\hline $\mathrm{BIC}$ & -3514.00 & & -3543.53 & & -1854.73 & & -1853.41 & \\
\hline
\end{tabular}

Significance: $*=10 \% ; * *=5 \% ; * * *=1 \%$. 